\title{
Self Incompatibility, Inbreeding Depression, and Potential to Develop Inbred Lines in Alfalfa: A Review
}
Atit Parajuli ${ }^{1}$, Longxi $\mathrm{Yu}^{2}$, Michael Peel ${ }^{3}$, Deven See ${ }^{4}$, Steve Wagner ${ }^{5}$, Steven Norberg ${ }^{6}$, and Zhiwu Zhang ${ }^{\text {* }}$

${ }^{1}$ Department of Crop and Soil Sciences, Washington State University, Pullman, WA 99164 , USA;

${ }^{2}$ Plant Germplasm Introduction and Testing Research, USDA-ARS and Washington State University, Prosser, WA 99350, USA;

${ }^{3}$ Forage \& Range Research Lab, USDA-ARS and Washington State University, Logan, UT 84322, USA;

${ }^{4}$ Wheat Health, Genetics, and Quality Research Unit, USDA-ARS and Washington State University, Pullman, WA 99164, USA;

${ }^{5}$ Alforex Seeds, West Salem, WI 54669, USA;

${ }^{6}$ Regional Forage Specialist and Irrigated Cropping Systems, Washington State University, Franklin County Extension Office, Pasco, WA 99301, USA

${ }^{*}$ Correspondence should be addressed to Zhiwu Zhang (email: Zhiwu.Zhang@,WSU.Edu)

\begin{abstract}
Alfalfa (Medicago sativa L.) is a perennial, outcrossing legume crop predominantly grown for hay, silage, or pasture. Intensive selection has resulted in dramatic improvement in fitness traits, including winter survival and disease resistance. However, there has been minimal improvement in other economically important traits, such as hay yield, which is still comparable to 30 years ago. Intensive phenotyping costs on this type of trait hinder high selection pressure to identify superior outcross individuals. Severe inbreeding depression inhibits the development of inbred lines with accumulated favorable alleles that exhibit heterosis. This review highlights the outcomes of inbreeding depression as well as the causes, including unmasking deleterious alleles and triggering self-incompatibility. We tracked the research efforts that unveil the genetic bases underlying deleterious alleles and self-incompatibility. The magnitudes of inbreeding depression were compared with the rate of heterozygous halved time in diploid and tetraploid organisms. To fill in the gaps between the controversy and existing hypotheses, we theorized a dosage dominant model of inheritance. The dosage dominant model is similar to the Mendelian dominance model, in which a genotype exhibits a dominant phenotype if there is a dominant allele (alphabet dominant). The difference is that in the dosage dominant model, a genotype will result in a dominant phenotype if the number of dominant alleles is equal to or greater than the number of recessive alleles. This review also includes a discussion on the development of pseudo inbreds and a hypothesis to identify deleterious alleles using bulked segregant analysis and consequently to purge deleterious alleles using marker-assisted selection, to progress toward the successful development of pure inbred lines in alfalfa.
\end{abstract}

Keywords: Hybrid Vigor, Heterosis, Bulked Segregant Analysis, and Marker Assisted Selection 


\section{Introduction}

Alfalfa (Medicago sativa L.) is a perennial and highly outcrossing legume forage crop grown predominantly for hay, silage, and pasture. Alfalfa exist in two ploidy levels (diploid, $2 \mathrm{n}=2 \mathrm{x}=$ 16; and tetraploid, $2 \mathrm{n}=4 \mathrm{x}=32$ ). Cultivated alfalfa is tetraploid with a base chromosome number of $x=8$ and a genome size of $\sim 3.15 \mathrm{~Gb}$ (Chen et al.,2020; Shen et al.,2020). It is an extremely important and widely cultivated crop worldwide due to its nutritious value. It is the third most valuable field crop produced in the U.S., valued at over $\$ 9.3$ billion (US Census, 2017). It also plays a significant role in providing ecosystem services, such as in soil fertility as it forms a symbiotic association with soil bacterium Sinorhizobium meliloti for atmospheric nitrogen fixation, supplying the alfalfa and improving nitrogen content in the soil for future crops. The perennial nature of the crop helps prevent soil erosion through deep root systems thereby maintaining soil quality.

Despite these benefits, genetic improvements in terms of forage yield have been limited in alfalfa (Figure 1) (Lamb et al., 2006; Riday et al., 2005; USDA, 2018). Studies suggested no significant yield improvement $(<1 \%)$ in alfalfa over the last half century (Holland \& Bingham, 1994). In comparison, the yield improvement in maize has been substantial, with a $2 \%$ increase per year since the extensive adoption of single-cross hybrids in the 1960s (Duvick, 1984). In alfalfa, genomic complexity, high inbreeding depression, and self-incompatibility complicate breeding procedures to improve production. Also, the stagnant yield is due to the focus of breeding programs on improvement of non-yield traits such as hay quality rather than breeding for yield (Lamb et al., 2006). Moreover, the perennial nature of alfalfa requiring multiple harvests, an inability to exploit heterosis in commercial cultivar(Tucak et al., 2012), and inefficient selection methods utilizing additive genetic variance (Casler \& Brummer, 2008; Kumar, 2011; Tucak et al., 2012) also contribute to slow yield improvement in alfalfa.

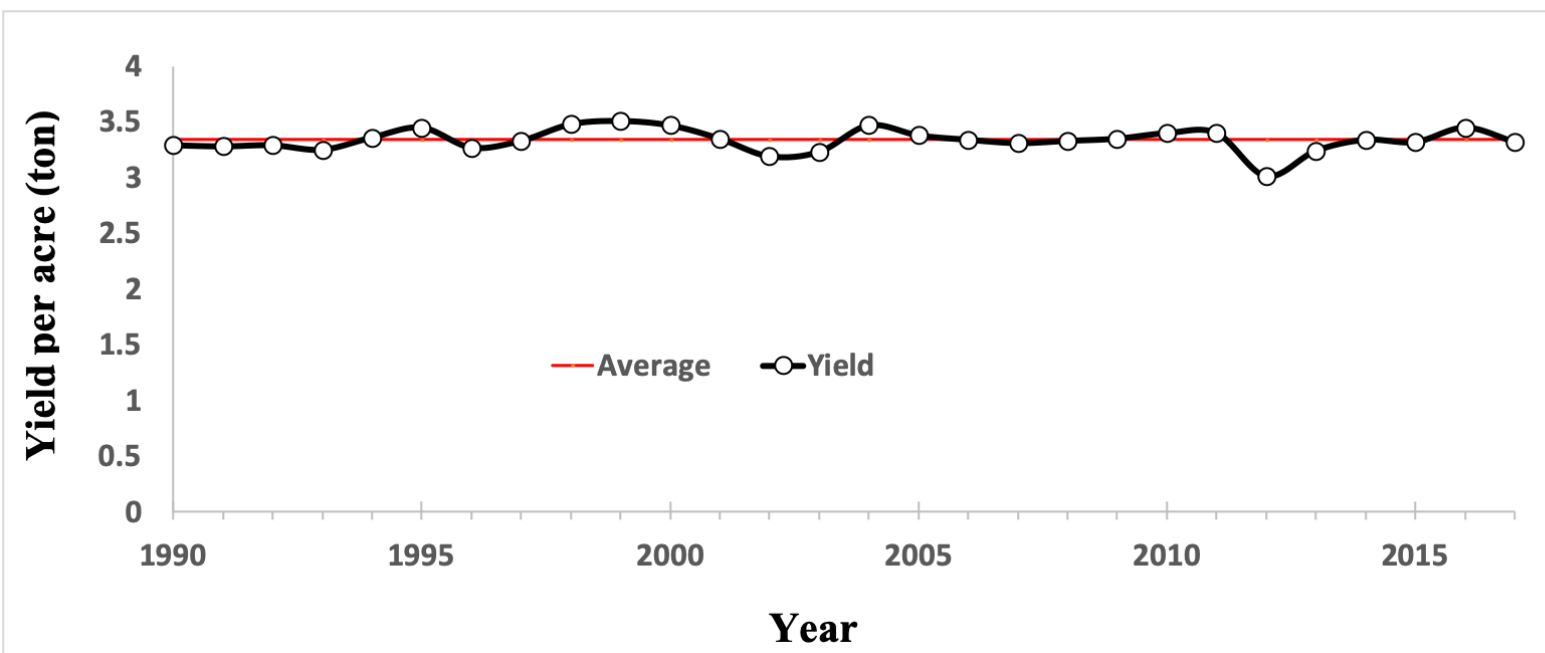

Figure 1. Alfalfa forage yield from 1990 - 2017 in the USA. Data taken from USDA Crop Production 2018 (USDA, 2018). The dots and black lines indicate the yield each year, and the red line indicates the average during the period.

The current alfalfa breeding programs are based on recurrent phenotypic selection. This method utilizes open pollinated crosses between selected parents to accumulate desirable alleles at high 
frequency (Li \& Brummer, 2012) for producing synthetic cultivars. Synthetic cultivars strive to fix favorable alleles and utilize intra-locus allelic interaction for increased production (Hill, 1987). However, low heritability of traits, size of the breeding population that can be evaluated in the field, and limited resources of breeding programs for assessing genotype $\mathrm{x}$ environment interaction (Li \& Brummer, 2012) seriously undermine the phenotypic selection process. Besides, genetic equilibrium upon the intercrossing of available germplasm (Barnes et al., 1977) may affect the future improvement process (Holland \& Bingham, 1994). Following in the footsteps of maize improvement, alfalfa breeding should focus on exploiting heterosis for genetic improvement.

Heterosis is the superior performance of progeny in relation to their parents. It forms the basis of genetic gain in maize and other crops. The expression of heterosis in population crosses requires directional dominance at loci controlling the trait of interest and differing allele frequencies at those loci in populations or lines to be crossed (Falcnor \& Mackay, 1996). Previous studies on alfalfa have shown the existence of heterosis (Bhandari et al., 2007; Lawati et al., 2010). Crosses between high-yielding alfalfa accessions demonstrate the possibility of developing high-yielding hybrids with improved performance over elite cultivars (Bhandari et al., 2007). The resulting genetic gain was achieved through the exploitation of both additive as well as non-additive genetic effects (Bhandari et al., 2007; Tucak et al., 2012). In alfalfa, approximately two-thirds of the variance for yield is non-additive(Dudley \& Busbice, 1969; Rowe \& Hill, 1981). These results indicate the potential for alfalfa to exploit heterosis for higher yield.

However, the major barrier to hybrid production in alfalfa is accumulation of the homozygous alleles for the traits of interest. High heterozygosity of the plants and severe inbreeding depression upon selfing prevent homozygosity among alleles, and ultimately, the development of pure inbred lines (Julier et al., 2003). Moreover, the problems associated with creating inbred lines and their use for the synthesis of new populations have not been adequately studied in alfalfa (Galiolla et al., 2018). The complexity of developing pure inbred lines in alfalfa forces breeding programs to use synthetic varieties as the most feasible means for genetic gain (Hill, 1987). Adding to this complexity, alfalfa requires pollinators which makes pollen control difficult. In order to address the problems associated with inbreeding depression and self-incompatibility for genetic improvement in alfalfa, we highlight causes based on past research on inbreeding depression and self-incompatibility.

Previous research implicated the loss of heterozygosity (Jones \& Bingham, 1995a), multiple allelic interactions (Busbice et al., 1966), and complementary gene action (Bingham et al., 1994) as major reasons for inbreeding depression in alfalfa. Similarly, a past study also pointed out the importance of loss of higher-order allelic interaction in alfalfa self-incompatibility (Viands et al., 1988). Still, the genetic mechanism behind self-incompatibility in alfalfa remains unexplained. In addition, alfalfa displays severe inbreeding depression similar to diploid species (Busbice \& Wilsie, 1966; Dewey, 1966, 1969) which is not clearly explained. To explain this ambiguity, we theorize a dosage dominant model of inheritance in this review. Moreover, we also hypothesize developing pure inbred lines through bulked segregant analysis followed by marker-assisted selection to identify and purge deleterious alleles. 


\section{Inbreeding depression}

Mating between individuals that are related by ancestry is termed inbreeding. Generally, inbreeding causes loss of vigor and decline in fitness in cross-pollinated species, known as Inbreeding Depression (Darwin, 1867). In his experiments, Darwin found considerable effects of inbreeding, such as late flowering, decreased weight, and fewer seeds than the outcrossing species. Also, he found significant reduction (41\%) in seed production and decline $(13 \%)$ in height (Frankham, 2002). Inbreeding causes loss of heterozygosity, which reduces the mean value of traits associated with fitness. As a result, it leads to inbreeding depression (Lynch \& Walsh, 1998) Another hypothesis argues that since most mutations are deleterious and generally recessive (Davenport, 1908; Mackay, 2001), increased homozygosity due to continuous inbreeding increases the possibility of unmasking deleterious alleles (Charlesworth \& Charlesworth, 1999), resulting in inbreeding depression (Keller \& Waller, 2002).

To sum up, deleterious recessive alleles in a cross-pollinating species remain hidden by their dominant counterparts and are not expressed phenotypically. Upon subsequent inbreeding, these deleterious alleles progressively fix to their homozygous form and express phenotypically, causing reduced vigor and fitness of individuals. However, the molecular basis underlying inbreeding depression as well as genes or gene pathways associated with inbreeding depression in crops are unknown (Paige, 2010). Additionally, the number of loci responsible for causing inbreeding depression of fitness and its components is also unknown (Frankham, 2002).

Alfalfa is a highly allogamous crop. Various studies show $89 \%$ natural crossing of alfalfa plants under field conditions(Bolton, 1948; Knowles, 1943; Pederson, 1953; Tysdel et al., 1942). Most alfalfa plants are found to be partially to completely self-incompatible (Viands et al., 1988) with a highly heterozygous population. Selfing these highly heterozygous individuals causes severe inbreeding depression due to the expression of deleterious recessive alleles in homozygous form. The higher sensitivity of alfalfa to inbreeding is shown in previous studies (Busbice et al., 1972; Tysdel et al., 1942). Kirk (1927) was the first to report a progressive decrease in vigor in alfalfa due to inbreeding. Wilsie (Wilsie, 1953) demonstrated an $80-90 \%$ loss of self-fertility and a 20 $30 \%$ decrease in vigor, upon one generation of selfing. Posler (Posler, 1969) also found a decline in fertility with rapid generation of inbreeding while employing selfing rather than sib mating. Similarly, Ray and Bingham (Ray \& Bingham, 1992) observed inbreeding depression using selfing in the first and second generations to be $49 \%$ and $26 \%$, respectively. Selfing alfalfa plants for successive generations increases inbreeding depression that results in reduced fitness making it difficult to develop pure inbred lines.

\section{Inbreeding depression due to deleterious alleles}

Populations exhibiting inbreeding depression carry a large number of deleterious alleles in the recessive form hidden at the heterozygous loci (Allard, 1960). This does not imply that all recessive alleles are harmful and dominant alleles are beneficial. Natural selection works against the dominant deleterious alleles, but recessive deleterious alleles survive in their recessive condition. These recessive deleterious alleles are masked by their dominant counterparts at their respective loci and passed from generation to generation. It is theorized that inbreeding depression is the result of increased homozygosity at loci affecting the trait of interest. As loci become 
171 homozygous, deleterious recessive alleles are unmasked from the effects of more favorable

172

173

174

175

176

177

178

179

180

181

182

183

184

185

186

187

188

189

190

191

192

193

194

195

196

197

198

199

200

201

202

203

204

205

206

207

208

209

210

211

212

213

214

215

216

dominant alleles(Jones \& Bingham, 1995b), resulting in inbreeding depression.

Three conditions are required for inbreeding depression to occur (Burton et al., 1978): 1) Presence of favorable and less favorable alleles at loci affecting the trait of interest in a population; 2) Dominance effect must be present among these alleles; and 3) Inbreeding must result in loss of heterozygosity at these loci. The synthetic nature of alfalfa cultivars and resulting highly heterozygous plants causes them to harbor a high amount of genetic load(Jones \& Bingham, 1995b), masked by their favorable dominant alleles. Genetic load is a measure of the number of recessive deleterious alleles in a population (Ness et al., 2004). Inbreeding causes loss of heterozygosity that results in unmasking of these harmful unfavorable alleles in their homozygous recessive form, causing inbreeding depression. Desirable alleles with additive and dominant effects contributing to heterosis and population improvement rarely have large positive effects but act cumulatively. Whereas recessive deleterious alleles contributing to inbreeding depression have been shown to have large effects on plant fitness and vigor (Genter, 1973).

It is difficult to explain inbreeding depression in alfalfa based only on decreased heterozygosity. As an autotetraploid species, alfalfa should have a slower rate of inbreeding depression than diploids, as heterozygosity is halved by 3.80 generations of selfing in autotetraploid compared to 1 generation of selfing in diploids(Dewey, 1966; Jones \& Bingham, 1995b). This requires an increased number of selfing generations to achieve similar levels of homozygosity relative to corresponding diploids. Still, alfalfa exhibits severe inbreeding depression, similar to diploids (Busbice et al., 1966; Dewey, 1966; Dewey, 1969). The reason for this ambiguity is assumed to be loss of multiple allelic interactions within a locus (Busbice et al., 1966). Progressive inbreeding fixes genes within a locus to their homozygous form, decreasing allelic interaction and resulting in high inbreeding depression. However, Bingham et al. (Bingham et al., 1994) proposed the idea of complementary gene action in autotetraploid alfalfa as a reason for high inbreeding depression. As an autotetraploid alfalfa has more significant complementary gene interaction than diploids, progressive selfing causes rapid loss of gene interaction due to decreased heterozygosity, thereby causing inbreeding depression. Although it is difficult to identify the main reason behind high inbreeding depression in alfalfa, this study implicates change in allelic frequency from heterozygosity to homozygosity as the major cause.

To explain similar inbreeding depression between diploid and tetraploid species, we theorized a dosage dominant model of inheritance to explain the possible interaction between dominant and recessive alleles (Figure 2). Under the conventional alphabet dominant model, a genotype containing one dominant allele exhibits the dominant phenotype. In contrast, under a dosage dominant model, a genotype exhibits a dominant phenotype only if the genotype comprises the same or more dominant alleles than recessive alleles. For diploid species, there is no difference between the alphabet dominant model and the dosage dominant model. However, the two models create different phenotypes among the same genotypes in polyploid species, such as an autotetraploid like alfalfa. Under the alphabet dominant model, selfing a heterozygote with the genotype of AAaa only generates 1/36 recessive homozygotes (aaa) exhibiting inbreeding depression, far less than the proportion ( $1 / 4)$ of recessive homozygotes in diploid species such as maize. Under the dosage dominant model, both genotypes of aaaa and Aaaa exhibit recessive phenotypes and occupy the same proportion as recessive phenotypes in diploid (1/4). This may 
217 explain why the autotetraploid alfalfa shows the same level of inbreeding depression as diploid 218 species (Busbice et al., 1966; Dewey, 1966; Dewey, 1969).

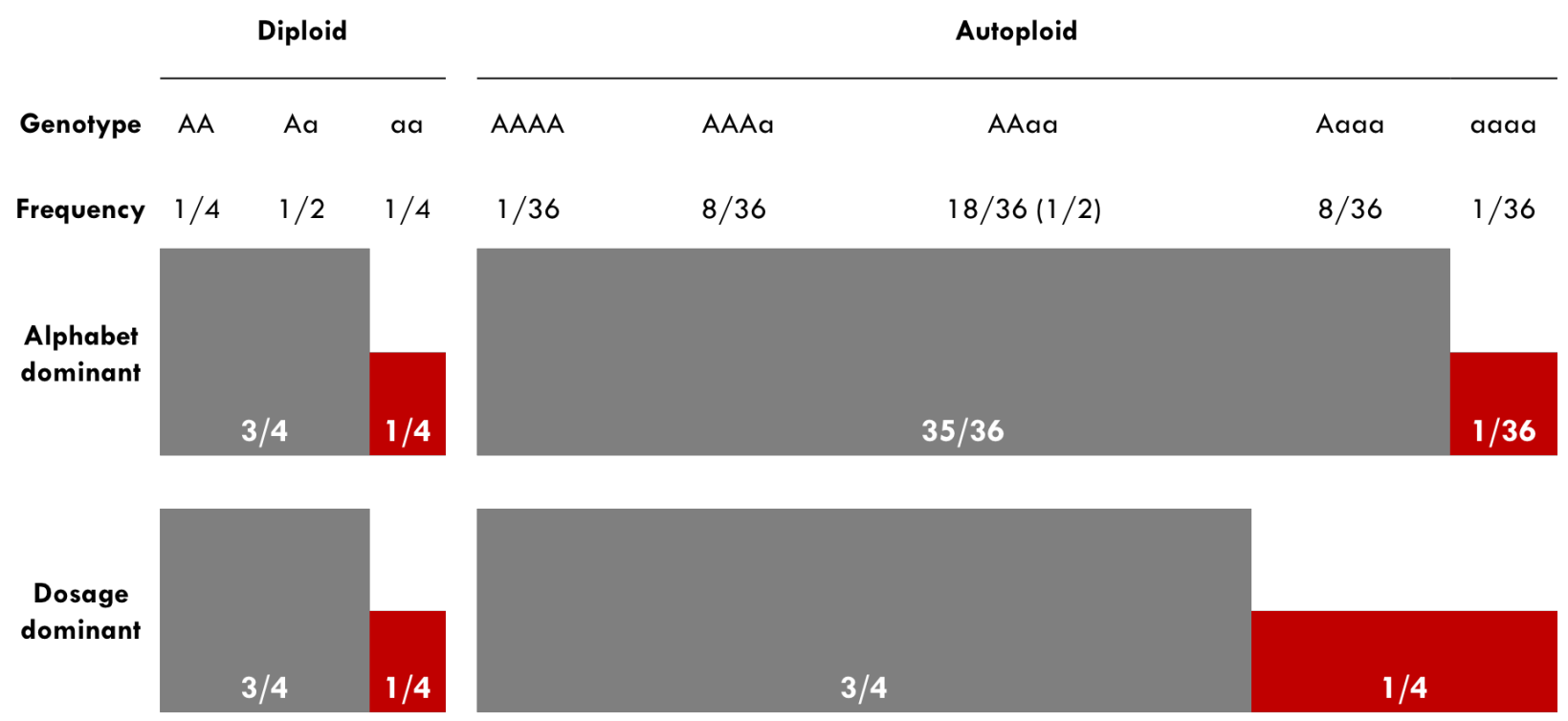

Figure 2. The alphabet and dosage dominant models of inheritance. Under the alphabet dominant model, a genotype exhibits a dominant phenotype as long as the genotype contains one dominant allele. In contrast, under the dosage dominant model, a genotype exhibits a dominant phenotype if the genotype comprises a number of dominant alleles that is equal to, or more than the number of recessive alleles. The alphabet dominant model and the dosage dominant model perform the same among progeny of selfing a diploid heterozygote with the genotype of Aa, where $\mathrm{A}$ is the dominant allele, and $\mathrm{a}$ is the recessive allele. The expected frequencies of the genotypes of AA, Aa, and aa are $1 / 4,1 / 2$, and $1 / 4$ respectively, among the progeny. The dominant phenotype (dark gray or tall bar) and recessive phenotype (red, or short bar) have a conventional Mendelian ratio of 3:1 under either alphabet or dosage dominant models. However, the two models perform differently for polyploids, such as autotetraploid. Among the progeny from selfing the heterozygote AAaa, the dominant phenotype (gray or tall bar) and recessive phenotype (red, or short bar) has a ratio of 35:1 under the alphabet model and a conventional Mendelian ratio of 3:1 under the dosage model.

\section{Inbreeding depression due to self-incompatibility}

Similar to inbreeding depression, self-incompatibility (SI) is also responsible for reduced seed set (decreased fitness) in alfalfa. However, the mechanism of lower fitness differs significantly. Selfincompatibility as defined by Nettancourt (Nettancourt, 2001) is the inability of a fertile hermaphrodite seed plant to produce zygote after self-pollination. It is a genetically determined physiological barrier preceding fertilization that allows pistil cells to discriminate between "self" and "non-self" pollen grains or pollen tubes, interfering with pollen germination at the surface of the stigma or pollen tube growth within the pistil (Nasrallah, 2017). Inbreeding depression is reduced survival, fitness and fertility of offspring of related individuals due to inbreeding(Charlesworth \& Willis, 2009), which is caused by unmasking of deleterious recessive alleles to their homozygous forms. Alfalfa flowers exhibit partial self-incompatibility (Brink et al. 1938). Different studies have indicated the differential pollen-tube growth of self and foreign 
pollen, along with partial incompatibility and embryo abortion following self-fertilization as compared to embryo development from cross-fertilization (Brink et al., 1936; Cooper, 1935; Cooper et al, 1937; Cooper et al.,1940). Pollen-stigma interaction, pollen tube-style interaction, and pollen tube-ovule interactions within the locule in self-incompatible plants were observed in populations of two pest-resistant varieties of alfalfa, W10 AC3 and BMP8 AC3 (Bauchan et al., 1990).

\section{Genetic basis of self-incompatibility}

Most flowering plants with perfect flowers (male reproductive organ and female reproductive organ on the same flower) have the tendency to self-fertilize. The prevalence of selfincompatibility in a species restricts the occurrence of inbreeding, which ultimately increases genetic variability. Self-incompatibility as defined by Mather (Mather, 1943) is the failure of a male and female gamete to achieve fertilization or form a zygote, after mating or pollination, where each of them is capable of uniting with other gametes of the breeding group after similar mating or pollination. So, self-incompatibility involves the rejection of related pollen by the pistil from the same flower before or at the time of fertilization. In general, self-incompatibility in plants is the consequence of the interaction between pollen-stigma, pollen tube-style, and pollen tube-ovule. The self-incompatible pistil recognizes genetically related (self) and genetically unrelated (nonself) pollen, thereby rejecting the self-pollen either on the surface of the stigma or during pollen tube growth in the stylar region.

The self-incompatibility reaction at the surface of the stigma is called the early-acting SI system, whereas the self-incompatibility reaction inside the stylar region is called the late-acting SI system. The recognition of self-pollen is based on allele-specific interactions (direct or indirect) of the pistil- and pollen-expressed products of S-locus genes(Rea \& Nasrallah, 2008). It triggers a cellular response in pistil or pollen, terminating with inhibition of pollen tube development. So far, three molecular mechanisms(Rea \& Nasrallah, 2008) of self-incompatibility have been identified based on molecular analysis of plant families (Brassicaceae, Solanaceae, Rosaceae, Scrophulariaceae, and Papaveraceae), in which it was determined that the recognition and response phases of selfincompatibility depend upon the site of pollen inhibition (i.e., whether it occurs early or late during the pollen tube's journey through the pistil, which in turn is determined by characteristics of the stigma surface)(Rea \& Nasrallah, 2008).

The first mechanism is known as the early-acting SI system. In this, the inhibition of pollen at the surface of the stigma occurs in the Brassicaceae family. The process is highly localized, involving a contact zone between pollen grain and stigmatic epidermal cells. Prevention of pollen germination and pollen tube growth at the surface of the stigma occurs due to the action of cell surface-localized receptors and ligands encoded by two S-locus genes: SRK (S-locus Receptor Kinase), which encodes a single-pass transmembrane serine/threonine kinase at the plasma membrane of the stigmatic epidermal cell (Takasaki et al., 2000); and S-locus Cysteine-Rich protein (SCR) (Schopfer et al., 1999; Suzuki et al., 1999), encoding a small peptide which functions as a ligand-receptor for SRK in the pollen coat. Interaction between SRK and SCR upon contact of pollen grain with the stigmatic surface results in specific recognition of selfed pollen (Shimosato et al., 2007), resulting in a self-incompatibility reaction. Therefore, in Brassicaceae, the incompatibility reaction is the result of the interaction of SCR and SRK, which activates the 
receptor's kinase to signal the epidermal layer of stigma, causing recognition and rejection of selfed pollen (Rea \& Nasrallah, 2008)

The second mechanism is called the late-acting SI system. It involves the death of a pollen tube inside the stylar region, also known as programmed cell death. It is observed in the Papaveraceae family. In programmed cell death, the germination of a pollen tube at the surface of the stigma is accompanied by the death of a pollen tube in the stylar region (Geitmann, 1999). In this system of SI, only the female determinant, which is responsible for the secretion of S protein, is reported. Secretion results in the influx of calcium inside the pollen tube, altering the normal cytosolic tipfocused calcium gradient that is responsible for maintaining the growth of the pollen tip (Franklintong et al., 2002). The calcium influx triggers events like actin depolymerization and disruption of the actin cytoskeleton (Snowman et al., 2002; Thomas et al., 2006), resulting in the inhibition of pollen tube growth. The male determinant of SI is proposed to be localized to the pollen tube plasma membrane. The SI system includes S-protein binding protein (SBP) and regulates calcium channel activity (Hearn et al.,1996). Identification of the male determinant of SI is essential to understand the role it has in programmed cell death of self-pollen tubes through interaction with the stigmatic $\mathrm{S}$ protein.

Finally, the third mechanism is the degradation of pollen RNA. It is observed in the upper third region of the style. It is affected by highly polymorphic pistil-specific glycoprotein S-RNase (Slocus ribonuclease) encoded by $\mathrm{S}$ locus and secreted into the extracellular matrix lining the path of pollen tube growth (Lee et al., 1994; Murfett et al., 1994). Although S-RNase RNA degradation activity is non-specific, it directs its activity towards self-pollen tubes when they are grown side by side with non-selfed pollen tubes in a pistil. It ultimately checks the growth of self-pollen tubes only. The role of S-RNase affecting S allele-specific inhibition of self-pollen tubes inside the pistil region is unknown.

In general, self-incompatibility in plants depends upon a highly polymorphic single locus called the S-locus having multiple alleles (Xiaoying et al,, 2011). The genetic basis of selfincompatibility on different families (Brassicaceae, Solanaceae, Rosaceae, Scrophulariaceae, and Papaveraceae) involves the S-locus gene, which recognizes related (selfed) and unrelated (nonselfed) pollen, resulting in the incompatibility reaction. However, the genetic basis of selfincompatibility cannot be explained by a highly polymorphic single locus called the S-locus in alfalfa. Sahni(Sahni, 1957) was unable to explain the self-incompatibility system in two diploid clones of Medicago species based on the S-locus. The absence of well-defined incompatibility relationships, coupled with the polyploid nature of the crop, makes it difficult to determine the genetic basis of self-incompatibility in alfalfa (Tysdel \& Kiesselbach, 1944). A simple inheritance pattern has not yet been established for self-incompatibility or self-sterility. However, loss of higher-order allelic interaction through inbreeding appears to be of major importance in alfalfa (Viands et al., 1988). Based on the preceding literature, the genetics behind self-incompatibility in alfalfa are still unclear. 


\section{Efforts to overcome inbreeding depression}

The out-crossing nature of the alfalfa plant and its polyploid genome create complexity in genetic improvement for higher forage and seed production. The prevalence of severe inbreeding depression prevents researchers from capturing heterosis in alfalfa cultivars through hybrid development. Consequently, it has led to a modification in breeding strategy for higher yield, by intercrossing selected parents to produce synthetic cultivars(Hill, 1987). This strategy is currently more feasible than the development of a hybrid cultivar. The intercrossing approach between plants with a broad genetic base increase heterozygosity, which increases the intra-locus interaction, and ultimately yield, in the cultivars. Inbreeding depression reduces the vigor of natural autotetraploid, while their performance is improved by maximizing heterozygosity (Dunbier \& Bingham, 1975). Maximum heterozygosity in alfalfa exploits intra-locus interaction as well as additive variation, eventually enhancing the performance of the crop.

A study on different years of alfalfa cultivars (1898-1985) indicated genetic improvement of alfalfa in terms of forage yield due to increased frequency of favorable alleles and utilization of nonadditive genetic effects (Holland \& Bingham, 1994). However, it also showed the increased amount of genetic load possessed by modern alfalfa cultivars (Holland \& Bingham, 1994). The study advocated reduction of genetic load in combination with diverse germplasm to enhance future yields. The broader genetic base of modern alfalfa cultivars likely masks the harmful deleterious alleles at their heterozygous loci. Genetic purging of these deleterious alleles provides a germplasm source for future improvement of alfalfa cultivars.

\section{Heterosis}

Although inbreeding depression is severe in alfalfa, the efforts for developing hybrids are still ongoing. In alfalfa, focus on improving traits, such as disease resistance and winter hardiness, controlled by major genes has limited performance improvement (Volenec et al., 2002). An improved breeding strategy would exploit non-additive gene interaction through heterosis. Currently the deleterious recessive alleles are passed from generation to generation, masked by their dominant counterparts. That makes it challenging to inhibit inbreeding depression in the succeeding generations of alfalfa (Busbice et al., 1972). As a result, it is difficult to develop inbred lines for hybrid production. However, studies have suggested (Busbice et al. , 1972; Tysdal et al., 1942) the potential for hybrids to contribute to overall production improvement in alfalfa.

Heterosis is the superior performance of offspring relative to their parents. The genetic basis of heterosis in alfalfa is partial to complete dominance (Bingham et al., 1994; Gallais, 1984; Woodfield \& Bingham, 1995). The hybrids would have full utilization of non-additive gene action along with additive, in comparison to synthetic counterparts with the potential for higher yield (Busbice et al., 1972). The first alfalfa hybrid developed in 1968 utilized the concept of cytoplasmic male sterility. Utilizing male sterility for hybrid seed production is difficult, as the autotetraploid nature of alfalfa complicates the inheritance of any gene associated with male sterility, Alternatively, the self-incompatibility mechanism in alfalfa for pollen control is not definitive(Barnes et al., 1977) for hybrid seed production. However, Dairyland Seed has been 
successful in utilizing cytoplasmic male sterility to control pollination in commercial hybrid seed production since 2000 .

A hybrid cultivar developed by Dairyland Seed Company called HybriForce-400 was found to perform consistently in the top 10\% when tested over 25 different environments (Wiersma, 2001) showing the stability of this hybrid variety. Riday et al. (Riday et al., 2005), with their study spanning 1998 through 2002, observed higher persistence from crosses between inter-subspecific hybrids (between Medicago sativa subspecies sativa and Medicago sativa subspecies falcata), which was equivalent to more persistent parental subspecies over time. They also observed 1020\% mid-parent heterosis for biomass yield in their study. Wagner et al. (2003), in their study of 326 hybrids from 2000 through 2002, observed average mid-parent and high-parent heterosis to be $3.4 \%$ and $1.6 \%$, respectively. However, values for mid-parent heterosis and high parent heterosis were observed as high as $13.1 \%$ and $9.3 \%$, respectively. The observed heterosis indicates the highly likelihood of identifying heterotic groups within alfalfa that could be utilized similar to that found in maize hybrids.

For commercial hybrid seed production in the field, controlled pollination is required, since uncontrolled pollination results in varying percentages of hybrid seed (Barnes et al., 1977). Controlled pollination could be achieved through self-incompatibility and genetic or cytoplasmic male sterility (Tysdal et al. , 1942; Barnes et al., 1977; Busbice et al., 1972). Intensive selection for self-sterility, without taking into account its nature, leads to cultivars with low seed production potential. However, selection for self-fertility may increase seed production potential while reducing the vigor of the inbred parent (Busbice et al., 1972). Therefore, male sterility is likely a better alternative for the production of hybrid cultivars. Expression of genetic male sterility requires homozygous recessive genotypes, so this technique has not been used to produce hybrid alfalfa cultivars. For that reason, cytoplasmic male sterility is likely the more efficient method for hybrid production in alfalfa (Barnes et al., 1977). The first commercial alfalfa hybrid utilized cytoplasmic male sterility in 1968. However, the non-preference of pollinators on the pollendeficient male sterile lines resulted in difficulty producing seed posing severe economic problems in the production of alfalfa hybrids (Viands et al., 1988). However, years of selection for improved seed yield in the male-sterile plant, improve pollination between the male-sterile plant and the male pollinizer plants and development of method to produce commercial hybrids that have at least $75 \%$ hybridity eventually made commercial hybrid seed production feasible and began being marketed by Dairyland Seed in 2001. An alternative to this method is to utilize female-sterile plants(Bingham et al., 1994) as a source of pollen for male-sterile plants. However, female sterility is controlled by single recessive genes and its maintenance requires outcrossing with female-fertile plants or clones. So, the application of this system is also limited for broader implementation.

\section{Genetic Gain}

Genetic gain in crop breeding is achieved through selection, recombination, and hybridization. Selection and recombination in diploids result in 1 5\% of genetic gain while hybridization results in more than $10 \%$ of genetic gain. In maize, significant yield improvement was achieved by shifting breeding strategies from open-pollinated varieties to hybrid varieties(Hallauer \& Miranda, 1988). Hybrid varieties efficiently utilize inputs like water, sunlight, and nutrients for higher yield. 
429

430

431

432

433

434

435

436

437

438

439

440

441

442

443

444

445

446

447

448

449

450

451

452

453

454

455

456

457

458

459

460

461

462

463

464

465

466

467

468

469

470

471

472

473

474
Prior to 2001, most of commercial alfalfa production uses synthetic cultivars. On-farm alfalfa yield of synthetic cultivars reported by USDA have increased over time, however, yield increase in recent decades have been limited. Wiersma et al. (1997) reported that yield levels in university variety trials from 1977 to 1992 did not improve. This lack of yield progress could be due, in part, to more aggressive cutting management of alfalfa to achieve better quality forage, and/or to higher levels of pathogen or other pest pressure. Direct measures of the genetic improvement in alfalfa yield over the last century are positive, but disappointing, ranging from $0.1 \%$ to $0.3 \%$ per year (Hill and Kalton, 1976; Hill and Rosenberger, 1985; Holland and Bingham, 1994). Wagner, et al. estimated alfalfa genetic gain directly by calculating the percent advantage of variety total accumulated yield over years against a standard check variety and regressing that against the year of varietal release (Wagner et al., 2010). They found that the genetic gain made by synthetic alfalfa varieties averaged $0.28 \%$ per year while that of hybrid alfalfa varieties was $0.56 \%$ per year. Hybrid alfalfa technology essentially doubled the rate of genetic gain. Following in the footsteps of maize breeding, alfalfa breeding should focus on the development of hybrid cultivars to overcome the bottleneck for yield improvement.

\section{Perspective}

Conventional breeding methods are time-consuming. They can be shortened by marker-assisted selection (MAS) (Yu, 2017) and genomic selection through rapid breeding cycles and fewer necessary phenotypic evaluations (Hawkins \& Yu, 2018). Additionally, advance sequencing technology and bioinformatics will provide in-depth knowledge of the molecular basis of inbreeding depression. A detailed understanding of the molecular basis of inbreeding depression will help with purging deleterious alleles from a population during selection. Recent sequencing technologies have been used to begin investigating the molecular basis of inbreeding depression. Pryce et al. (Pryce et al., 2014) identified genomic regions associated with inbreeding depression in cattle. Further advancement of genotyping technologies coupled with genome-wide association mapping of deleterious alleles will enhance understanding of inbreeding depression.

In alfalfa, natural selection by inbreeding depression (NSID) restricts seed production past the fourth generation of inbreeding. Previous studies used NSID alone to remove deleterious alleles, which seriously undermined fertility and survivability in the progeny. Through marker-assisted selection, deleterious alleles responsible for reduced fitness can be identified and purged from the population before being fixed to their homozygous recessive form (Figure 3). MAS could help in the identification of change in allele frequencies within the genome to monitor specific alleles or haplotypes (Steele et al., 2004). It can be used to develop lines with particular allele combinations through the early generations of selection (Ribaut et al., 2001; Steele et al., 2004). Consequently, the combination of MAS and NSID will facilitate the purge of deleterious recessive alleles in the early generations of selfing and retain seed producing individuals. This will ultimately increase equilibrium for seed production and result in inbred lines free of deleterious alleles.

In alfalfa, the proportion of heterozygous genes is higher than homozygous genes due to their high outcrossing nature. As a result, deleterious alleles can easily pass through generations masked by their dominant counterparts. Inbreeding in alfalfa increases the expression of deleterious recessive 
475

476

477

478

479

480

481

482

483

484

alleles in their homozygous form (Figure 3) and as a result the inbreeding depression alone eliminates seed production after the fourth generation in the inbred progeny. So, it is important to map genetic loci associated with inbreeding depression in alfalfa and purge the deleterious alleles. To this end, the phenotypic variation of fertility in alfalfa, which produces high- and low-seeded individuals due to inbreeding, allows the identification of genetic loci associated with fertility. Genotyping inbred individuals with differential rates of fertility enables the identification of both genetic loci and genetic variants associated with the loci. These identified genetic variants can be used as molecular markers in the next generation of selection to purge deleterious recessive alleles from the population. The process of eliminating individuals with deleterious recessive alleles from the inbreeding population is presented in Figure 3.

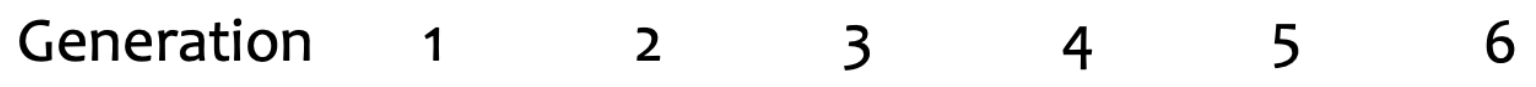

NSID only
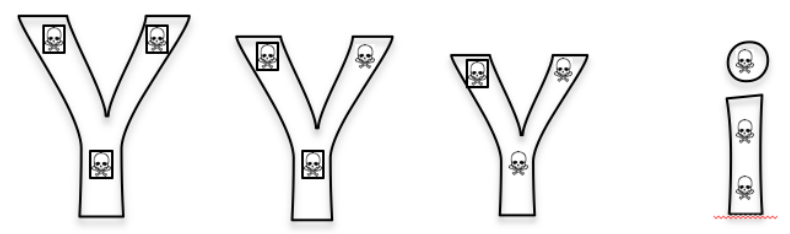

NSID + MAS
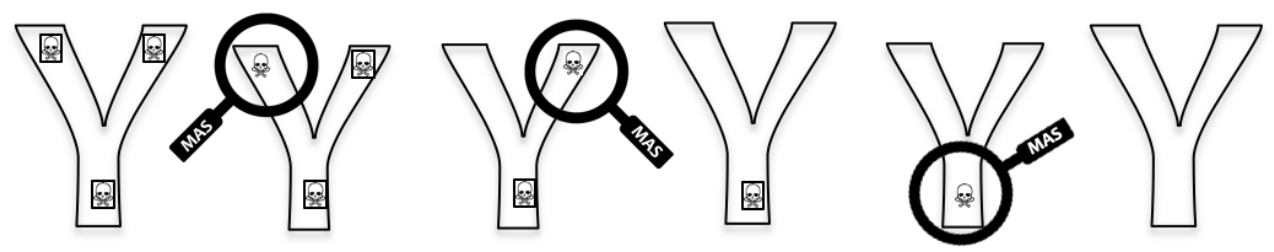

\section{NSID: Natural Selection by Inbreeding MAS: Marker Assisted Selection Depression}

\section{P Plant able to seed} deleterious alleles.

\section{Deleterious allele as}

sing un-harmful heterozygous

\section{\. Plant unable to seed}

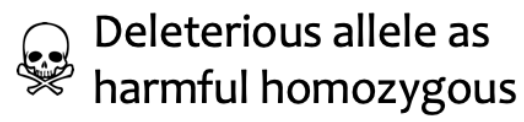

Figure 3. Marker-assisted selection and natural selection by inbreeding depression to purge deleterious alleles. A fertile plant (Y) becomes less fertile during inbreeding when deleterious alleles appear from increasing homozygosity, reducing fertility and eventually resulting in an infertile plant (i). The addition of MAS reduces inbreeding depression by efficiently purging

Marker-assisted selection can help natural selection by inbreeding depression to purge harmful deleterious recessive alleles from the population of inbreeding individuals. Inbreeding increases homozygosity and reduces heterozygosity by half per generation but applying natural selection alone cannot identify the presence of deleterious alleles in their heterozygous form (Figure 3, NSID only generations 1, 2, and 3). Once these deleterious recessive alleles are expressed in their homozygous form (Figure 3, NSID only, generation 4), reduced fitness in individuals eliminates seed production. However, the addition of marker-assisted selection helps to identify these deleterious recessive alleles even when they are masked by their dominant counterparts in the heterozygous form (Figure 3, NSID + MAS, generations 1, 2, 3, 4, 5, and 6). As a result, they are 
501 subsequently purged from the inbreeding individuals, leading to the development of pure inbred 502 lines through inbreeding up to the sixth generation. These inbred lines could then be tested to 503 identify heterotic groups with good combining ability. And then, they could be used directly in the 504 breeding programs for developing hybrids or could be used further to create novel recombination 505 506 lines. Additionally, the generation of inbred lines could be used to incorporate traits of interest such as tolerance to biotic and abiotic stress that could then be combined into hybrids that combine the desirable traits from both the parents.

514

515

516

517

518

519

520

521

522

523

524

525

526

527

528

529

530

531

532

533

534

535

536

537

538

539

540

541

542

543

\section{Conclusion}

Alfalfa is a major forage crop around the world and is the third most valuable field crop produced in the U.S. Genetic improvement in alfalfa has occurred at a slower pace than in other crops. Conventional breeding approaches have not exploited the full yield potential. In addition, genomic complexity, severe inbreeding depression, and high-outcrossing nature make it difficult to effectively improve complex agronomic traits associated with production. The use of synthetic cultivars does not maximize genetic potential and ultimately increase production. Similar to maize, in which significant genetic gain was achieved through the exploitation of heterosis, it would be beneficial if alfalfa breeding programs shift from synthetic to hybrid cultivars. Probably the major setback for hybrid production is the inability to produce pure inbred lines due to severe inbreeding depression and partial self-incompatibility. Recent advancements in bioinformatics and sequencing technology have started to provide insight into the molecular basis of inbreeding depression and self-incompatibility. Mapping deleterious alleles through advance genotyping and genome-wide association study will help to identify genetic variants associated with inbreeding depression. The identified genetic variants can be used as markers which will help to purge deleterious alleles that cause inbreeding depression in the early generations of breeding cycles. Consequently, it will increase the probability to produce fertile inbred lines in the succeeding generations. The successful development of fertile inbred lines would potentially lead to significant changes in the alfalfa industry that will provide benefits to alfalfa breeders. The development of inbred lines will facilitate alfalfa breeders to produce superior hybrids. Furthermore, the successful mapping of genetic loci associated with inbreeding depression in alfalfa opens up avenues of improvement for breeding other crops with high inbreeding depression and self-incompatibility.

\section{Acknowledgment}

The authors thank Cari Park for copy-editing the manuscript.

\section{Funding}

This project was funded by USDA NIFA (Hatch project 1014919, 2018-70005-28792, 201967013-29171, and 2020-67021-32460), and Washington Grain Commission (Endowment and Award \#s 126593 and 134574). 


\section{References}

Allard, R. W. (1960). Principles of Plant Breeding. Wiley.

Barnes, D. K., Bingham, E. T., Murphy, R. P., Hunt, O. J., Beard, D. F., Skrdla, W. H., \& Teuber, L. R. (1977). Alfalfa Germplasm in the United States: Genetic Vulnerability, Use, improvement and maintenance (Vol. 1571). https://doi.org/10.22004/ag.econ.157857

Bauchan, G. R., Campbell, T. A., Neill, N. R. O., \& Elgin, J. H. (1990). Self-Incompatibility in Two Alfalfa Populations. Crop Science, 30(6), 1205-1210. https://doi.org/10.2135/cropsci1990.0011183X003000060009x

Bhandari, H. S., Pierce, C. A., Murray, L. W., \& Ray, I. M. (2007). Combining Abilities and Heterosis for Forage Yield among High-Yielding Accessions of the Alfalfa Core Collection. Crop Science, 47(2), 665-671. https://doi.org/10.2135/cropsci2006.06.0398

Bingham, E. T., Groose, R. W., Woodfield, D. R., \& Kidwell, K. K. (1994). Complementary gene interactions in alfalfa are greater in autotetraploids than diploids. Crop Science, 34(4), 823-829. https://doi.org/10.2135/cropsci1994.0011183X003400040001x

Bolton, J. L. (1948). A Study of Combining Ability of Alfalfa in Relation to Certain Methods of Selection. Scientific Agriculture, 28(3), 97-126.

Brink, R. A., \& Cooper, D. C. (1936). The Mechanism of Pollination in Alfalfa ( Medicago Sativa ). American Journal of Botany, 23(10), 678-683.

Brink, R. A., \& Cooper, D. C. (1938). Partial Self-Incompatibility in Medicago Sativa. Proceedings of the National Academy of Sciences, 24(11), 497-499. https://doi.org/10.1073/pnas.24.11.497

Burton, J W. Stuber, C W. Moll, R. H. (1978). Variability of Response to Low Levels of Inbreeding in a Population of Maize. Crop Science, 1975, 65-68. https://doi.org/10.2135/cropsci1978.0011183X001800010018x

Busbice, T. H., Hill, R. R., \& Carnahan, H. L. (1972). Genetics and Breeding Procedure. In C. H. Hanson (Ed.), Alfalfa Science and Technology (Agronomy M, pp. 283-318). https://doi.org/10.2134/agronmonogr15.c13

Busbice, T. H., \& Wilsie, C. P. (1966). Inbreeding Depression and Heterosis in Autotetraploid with Application in Medicago sativa L. Euphytica, 15, 52-67.

Casler, M. D., \& Brummer, E. C. (2008). Theoretical Expected Genetic Gains for Among-andWithin-Family Selection Methods in Perennial Forage Crops. Crop Science, 48(3), 890902. https://doi.org/10.2135/cropsci2007.09.0499

Charlesworth, B., \& Charlesworth, D. (1999). The genetic basis of inbreeding depression. Genetics Research, 74(3), 329-340. https://doi.org/10.1017/S0016672399004152

Charlesworth, D., \& Willis, J. H. (2009). The genetics of inbreeding depression. Nature Reviews Genetics, 10(11), 783-796. https://doi.org/10.1038/nrg2664

Chen, H., Zeng, Y., Yang, Y., Huang, L., Tang, B., Zhang, H., Hao, F., Liu, W., Li, Y., Liu, Y., Zhang, X., Zhang, R., Zhang, Y., Li, Y., Wang, K., He, H., Wang, Z., Fan, G., Yang, H., ... Qiu, Q. (2020). Allele-aware chromosome-level genome assembly and efficient transgenefree genome editing for the autotetraploid cultivated alfalfa. Nature Communications, 11(1), 2494. https://doi.org/10.1038/s41467-020-16338-x

Cooper, D. C. (1935). Microsporogenesis and Emryology of Medicago. Journal of Agricultural Research, 51(5), 471-477.

Cooper, D. C., \& Brink, R. A. (1940). Partial self-incompatibility and the collapse of fertile ovules as factors affecting seed formation in alfalfa. Journal of Agricultural Research, 60, 

453-472.

D K Barnes, E T Bingham, R. P. M. (1977). No Title.

Darwin, C. (1867). The Effects of Cross and Self-Fertilization in the Vegetable Kingdom.

Davenport, C. B. (1908). Degeneration, Albinism and Inbreeding. Science, 28(718), 454-455. https://doi.org/10.1126/science.28.718.454-b

Dewey, D. R. (1966). Inbreeding Depression in Diploid, Tetraploid, and Hexaploid Crested Wheatgrass. Crop Science, 6(2), 144-147. https://doi.org/10.2135/cropsci1966.0011183X000600020011x

Dewey, D. R. (1969). Inbreeding depression in Diploid and induced Tetraploid Crested Wheatgrass. Crop Science, 9(5), 592-595. https://doi.org/10.2135/cropsci1969.0011183X000900050023x

Dudley, J. W., \& Busbice, T. H. (1969). Estimates of Genetic Variance in 'Cherokee' Alfalfa (Medicago sativa, L.). Crop Science, 9(2), 228-231. https://doi.org/10.2135/cropsci1969.0011183X000900020036x

Dunbier, M. W., \& Bingham, E. T. (1975). Maximum Heterozygosity in Alfalfa: Results Using Haploid-derived Autotetraploids. Crop Science, 15(4), 527-531. https://doi.org/10.2135/cropsci1975.0011183X001500040023xa

Duvick, D. N. (1984). Genetic Contributions to Yield Gains of Five Major Crop Plants. CSSA Special Publication. https://doi.org/10.2135/cssaspecpub7.c2

Falcnor, D. S., \& Mackay, T. F. C. (1996). Introduction to Quantitative Genetics. Longman.

Frankham, R., Ballou, J. D., \& Briscoe, D. A. (2002). Introduction to Conservation Genetics. Cambridge University Press.

Franklin-tong, V. E., Holdaway-clarke, T. L., Straatman, K. R., \& Kunkel, J. G. (2002). Involvement of Extracellular Calcium Influx in the Self-Incompatibility Response of Papaver Rhoeas. The Plant Journal, 29(3), 333-345. https://doi.org/10.1046/j.1365313x.2002.01219.x

Galiolla, M., Serik, K., \& Sakysh, Y. (2017). Results of Selection Studies of Alfalfa Based on Inbred Lines. Journal of Agricultural Science and Technology, 309-316. https://doi.org/10.17265/2161-6256/2017.05.003

Gallais, A. (1984). An Analysis of Heterosis VS. Inbreeding Effects with an Autotetraploid Cross-Fertilized Plant: Medicago sativa L. Genetics, 106(1), 123-137.

Geitmann, A. (1999). Cell Death of Self-incompatible Pollen Tubes: Necrosis or Apoptosis? Fertilization in Higher Plants, 113-137.

Genter, C. F. (1973). Comparison of S1 and Testcross Evaluation after Two Cycles of Recurrent Selection in Maize. Crop Science, 13(5), 524-527. https://doi.org/10.2135/cropsci1973.0011183X001300050009x

Hallauer, A. R., \& Miranda, J. B. (1988). Quantitative Genetics in Maize Breeding (Second). Iowa state university press.

Hawkins, C., \& Yu, L. (2018). Recent progress in alfalfa ( Medicago sativa L .) genomics and genomic selection. The Crop Journal, 6(6), 565-575. https://doi.org/10.1016/j.cj.2018.01.006

Hearn, M. J., Christopher, F., Franklin, H., \& Ride, J. P. (1996). Identification of a membrane glycoprotein in pollen of Papver rhoeas which binds stigmatic self-incompatibility (S-) proteins. The Plant Journal, 9(4), 467-475. https://doi.org/10.1046/j.1365313X.1996.09040467.x 
Development. Volume 1 Theory and Technique. Macmillan.

Holland, J. B., \& Bingham, E. T. (1994). Genetic Improvement for Yield and Fertility of Alfalfa Cultivars Representing Different Eras of Breeding. Crop Science, 34(4), 953-957. https://doi.org/10.2135/cropsci1994.0011183X003400040022x

Jones, J. S., \& Bingham, E. T. (1995a). Plant Breeding Reviews. In J. Janick (Ed.), Plant Breeding Reviews. https://doi.org/10.1002/9780470650059.ch6

Jones, J. S., \& Bingham, E. T. (1995b). Plant Breeding Reviews. In J. Janick (Ed.), Plant Breeding Reviews. Wiley. https://doi.org/10.1002/9780470650059.ch6

Julier, B., Flajoulot, S., Barre, P., Cardinet, G., Santoni, S., Huguet, T., \& Huyghe, C. (2003). Construction of two genetic linkage maps in cultivated tetraploid alfalfa (Medicago sativa) using microsatellite and AFLP markers. BMC Plant Biology, 3(9), 1-19. https://doi.org/10.1186/1471-2229-3-9

Keller, L. F., \& Waller, D. M. (2002). Inbreeding effects in wild populations. Trends in Ecology and Evolution, 17(5), 230-241. https://doi.org/10.1016/S0169-5347(02)02489-8

Kirk, L. E. (1927). Self-fertilization in relation to forage crop improvement. Scientific Agriculture, 8, 1-40. https://doi.org/10.4141/sa-1927-0076

Knowles, R. P. (1943). The Role of Insects, Weather Condition and Plant Character in Seed setting of Alfalfa. Scientific Agriculture, 24(1), 29-50. https://doi.org/10.4141/sa-19430063

Kumar, S. (2011). Biotechnological advancements in alfalfa improvement. Journal of Applied Genetics, 52, 111-124. https://doi.org/10.1007/s13353-011-0028-2

Lamb, J. F. S., Sheaffer, C. C., Rhodes, L. H., Sulc, R. M., Undersander, D. J., \& Brummer, E. C. (2006). Five Decades of Alfalfa Cultivar Improvement: Impact on Forage Yield, Persistence, and Nutritive Value. Crop Science, 46(2), 902-909. https://doi.org/10.2135/cropsci2005.08-0236

Lawati, A. H. A., Pierce, C. A., Murray, L. W., \& Ray, I. M. (2010). Combining Ability and Heterosis for Forage Yield among Elite Alfalfa Core Collection Accessions with Diff erent Fall Dormancy Responses. Crop Science, 50(1), 150-158. https://doi.org/10.2135/cropsci2008.09.0549

Lee, H., Huang, S., \& Kao, B. T. (1994). S proteins control rejection of incompatible pollen in Petunia inflata. Nature, 367(February), 560-563. https://doi.org/10.1038/367560a0

Li, X., \& Brummer, C. (2012). Applied Genetics and Genomics in Alfalfa Breeding. Agronomy, 2(1), 40-61. https://doi.org/10.3390/agronomy2010040

Lynch, M., \& Walsh, B. (1998). Genetics and analysis of quantitative traits. MA: Sinauer.

Mackay, T. F. C. (2001). Genetic Architecture of Quantitative trait. Annual Review in Genetics, $35,303-339$.

Mather, K. (1943). Specific Differences in Petunia: I. Incompatibility. Journal of Genetics, 45, 215-235.

Murfett, J., Atherton, T. L., Mou, B., Gassert, C. S., \& McClure, B. A. (1994). S-RNase expressed in transgenic Nicotiana causes S-allele-specific pollen rejection. Nature, 367, 563-566. https://doi.org/10.1038/367563a0

Nasrallah, J. B. (2017). Plant mating systems : self-incompatibility and evolutionary transitions to self-fertility in the mustard family. Current Opinion in Genetics \& Development, 47, 5460. https://doi.org/10.1016/j.gde.2017.08.005

Ness, B. D., \& Knight, J. . (2004). Encyclopedia of Genetics.

Nettancourt, de D. (2001). Incompatibility and incongruity in wild and cultivated plants. 
Paige, K. N. (2010). The Functional Genomics of Inbreeding Depression : A New Approach to an Old Problem. BioScience, 60(4), 267-277. https://doi.org/10.1525/bio.2010.60.4.5

Pederson, M. W. (1953). Preliminary Studies on Breeding Alfalfa for Seed Production in Utah. Agronomy Journal, 45(5), 179-182. https://doi.org/10.2134/agronj1953.00021962004500050001x

Posler, G. L. (1969). Inbreeding alfalfa, Medicago sativa L, by selfing, sib-mating , and backcrossing. Iowa State University.

Pryce, J. E., Haile-mariam, M., Goddard, M. E., \& Hayes, B. J. (2014). Identification of genomic regions associated with inbreeding depression in Holstein and Jersey dairy cattle. Genetics Selection Evolution, 46(1), 1-14. https://doi.org/10.1186/s12711-014-0071-7

Ray, I. M., \& Bingham, E. T. (1992). Inbreeding Cultivated Alfalfa at the Diploid Level by Selfing and Sib-mating. Crop Science, 32, 336-339. https://doi.org/10.2135/cropsci1992.0011183X003200020011x

Rea, A. C., \& Nasrallah, J. B. (2008). Self-incompatibility systems : barriers to self-fertilization in flowering plants. The International Journal of Developmental Biology, 52(July), 627636. https://doi.org/10.1387/ijdb.072537ar

Ribaut, M. J., Williams, M. H., Khairallah, M., Worland, J. A., \& Hoisington, D. (2001). Application of Physiology in Wheat Breeding. In Application of Physiology in Wheat Breeding.

Riday, H., Brummer, E. C., \& Salem, W. (2005). Heterosis in a Broad Range of Alfalfa Germplasm. Crop Science, 45(1), 8-17. https://doi.org/10.2135/cropsci2005.0008a

Rowe, D. E., \& Hill, R. R. (1981). Inter-population Improvement Procedures for Alfalfa. Crop Science, 21(3), 392-397. https://doi.org/10.2135/cropsci1981.0011183X002100030010x

Sahni, V. M. (1957). Genetics of self-incompatibility in alfalfa. Purdue University.

Schopfer, C. R., Nasrallah, M. E., \& Nasrallah, J. B. (1999). The Male Determinant of SelfIncompatibility in Brassica. Science, 286(5445), 1697-1700. https://doi.org/10.1126/science.286.5445.1697

Shen, C., Du, H., Chen, Z., Lu, H., Zhu, F., Chen, H., Meng, X., Liu, Q., Liu, P., Zheng, L., Li, X., Dong, J., Liang, C., \& Wang, T. (2020). The Chromosome-Level Genome Sequence of the Autotetraploid Alfalfa and Resequencing of Core Germplasms Provide Genomic Resources for Alfalfa Research. Molecular Plant, 13(9), 1250-1261. https://doi.org/10.1016/j.molp.2020.07.003

Shimosato, H., Yokota, N., Shiba, H., Iwano, M., Entani, T., \& Che, F. (2007). Characterization of the SP11/SCR High-Affinity Binding Site Involved in Self/Nonself Recognition in Brassica Self-Incompatibility. The Plant Cell, 19(1), 107-117. https://doi.org/10.1105/tpc.105.038869

Snowman, B. N., Kovar, D. R., Shevchenko, G., Franklin-tong, V. E., \& Staiger, C. J. (2002). Signal-Mediated Depolymerization of Actin in Pollen during the Self-Incompatibility Response. The Plant Cell, 14(10), 2613-2626. https://doi.org/10.1105/tpc.002998

Steele, K. A., Edwards, G., Zhu, J., \& Witcombe, J. K. (2004). Marker-evaluated selection in rice : shifts in allele frequency among bulks selected in contrasting agricultural environments identify genomic regions of importance to rice adaptation and breeding Bulk. Theoretical and Applied Genetics, 109(6), 1247-1260. https://doi.org/10.1007/s00122-0041732-7

Steve Wagner, Paul Sun, Mike Velde, and D. G. (2003). Heterosis in Hybrid Alfalfa.

Suzuki, G., Kai, N., Hirose, T., Fukui, K., Nishio, T., Takayama, S., Isogai, A., Watanabe, M., \& 
Hinata, K. (1999). Genomic Organization of the S Locus : Identification and Characterization of Genes in SLG / SRK Region of S 9 Haplotype of Brassica campestris ( syn . rapa ). Genetics, 153(1), 391-400.

Takasaki, T., Hatakeyama, K., \& Suzuki, G. (2000). The S receptor kinase determines selfincompatibility in Brassica stigma. Nature, 403(6772), 913-916. https://doi.org/10.1038/35002628

Thomas, S. G., Huang, S., Li, S., Staiger, C. J., \& Franklin-tong, V. E. (2006). Actin depolymerization is suffi cient to induce programmed cell death in self-incompatible pollen. Journal of Cell Biology, 174(2), 221-229. https://doi.org/10.1083/jcb.200604011

Tucak, M., Cupic, T., Spanic, V., \& Meglic, V. (2012). Combining abilities and heterosis for dry matter yield in alfalfa diallel crosses. Romanian Agricultural Research, 29(29), 71-77.

Tysdal, H. M., Kiesselbach, T. A., \& Westover, H. . (1942). Alfalfa Breeding.

Tysdel, H. M., \& Kiesselbach, T. A. (1944). Hybrid Alfalfa. Agronomy, 36, 649-667.

Tysdel, H. M., Klesselbach, T. A., \& Westover, H. M. (1942). Alfalfa Breeding.

USDA. (2018). Crop Production Historical Track Records. National Agricultural Statistics Service, USDA, April.

Viands, D. R., Sun, P., \& Barnes, D. K. (1988). Pollination Control: Mechanical and Sterility. In Alfalfa and Alfalfa Improvement (p. Page 931-960).

Volenec, J. J., Cunningham, S. M., \& Haagenson, D. M. (2002). Physiological genetics of alfalfa improvement : past failures, future prospects. Field Crop Research, 75(2-3), 97-110. https://doi.org/10.1016/S0378-4290(02)00020-5

Wiersma, D. W. (2001). Are Hybrids the New Yield Force in Alfalfa? A Summary of Alfalfa Hybrid Performance in University Variety Trials. In Focus on Forage (Issue 12).

Wilsie, C. P. (1953). Effect of Inbreeding on Fertility and Vigor of Alfalfa. Agronomy Journal, 50(4), 182-185. https://doi.org/10.2134/agronj1958.00021962005000040004x

Woodfield, D. R., \& Bingham, E. T. (1995). Improvement in Two-Allele Autotetraploid Populations of Alfalfa Explained by Accumulation of Favorable Alleles. Crop Science, 35(4), 988-994. https://doi.org/10.2135/cropsci1995.0011183X003500040010x

Xiaoying, M., Sun, P., \& Kao, T. (2011). S-RNase-based self-incompatibility in Petunia inflata. Annals of Botany, 108(4), 637-646. https://doi.org/10.1093/aob/mcq253

Yu, L. (2017). Identification of Single-Nucleotide Polymorphic Loci Associated with Biomass Yield under Water Deficit in Alfalfa (Medicago sativa L .) Using Genome-Wide Sequencing and Association Mapping. Frontiers in Plant Science, 8(June), 1-11. https://doi.org/10.3389/fpls.2017.01152 